"grand rounds" mainly for hospital staff, there are courses, conferences, and lectures concerning topics of community and family medicine. A library is open to all doctors in the locality, and in many there are a variety of audiovisual aids and study rooms. Catering and bar facilities enhance the club atmosphere, and lunch-time sessions are useful to busy general practitioners.

If continuing education is now well catered for vocational training is not so as yet. But suitable schemes such as those associated with day-release are being evolved and put into effect. One of the difficulties highlighted at the association's meeting was how to reconcile the calls of good vocational training with service needs. There was a division of opinion among tutors about the role of the universities, some suggesting that they contributed little and had no place to play in the postgraduate educational field. Others, however, had obtained considerable help from their university connections and it seemed that these opinions reflected the differing conditions from region to region. It is reasonably certain that the university/regional hospital board symbiosis envisaged by the Ministry of Health in 1964 will be more fruitful than either body alone, and any variations encountered are likely to result from the personalities involved rather than from the system. The centres which grew up as an essential instrument of continuing medical education will become equally essential for proper vocational training. It is important therefore that the centres-though their facilities may be made available to groups allied to medicine-should keep their own identity as educational and academic centres for doctors and that they should continue to be controlled by the clinical tutor. The great expansion in teaching is throwing a strain on many who are called upon to prepare and deliver lectures or to help in some other formal way, and this should be provided for by allowing for teaching sessions in their contracts. The momentum which has been gained must not be lost before the goals have been reached.

${ }_{1}^{1}$ British Medical Fournal, 1962, 1, 466

2 Report of the Royal Commission on Medical Education, 1965-8. London, H.M.S.O., 1968.

${ }^{3}$ Lister, J., unpublished data.

\section{Spontaneous Pneumothorax and Apical Lung Disease}

Though spontaneous pneumothorax can occur at any age and result from a variety of chronic lung diseases, it most often afflicts young men with good previous health and normal chest radiographs. ${ }^{1}$ In this group of patients the aetiology is obscure, though thoracotomy will often disclose a ruptured subpleural emphysematous bulla. ${ }^{2}$

I. Lichter and J. F. Gwynne ${ }^{3}$ have recently described the pathological findings in 20 such patients who came to thoracotomy because the pneumothorax was either persistent or recurrent. In every case a lesion was found in the apex of the upper lobe, and in most of them the remainder of the lung seemed healthy. The lesion was usually less than 2 or 3 $\mathrm{cm}$ in diameter and consisted of an area of fibrosis and collapse surmounted by one or more thin-walled air cysts. Microscopy showed inflammatory changes which were attributed to non-specific infection.

This apical localization of the causative lesion may be relevant to the pathogenesis of "idiopathic" pneumothorax.
There are several factors which could determine whether a disease process affects chiefly the upper or the lower parts of the lung. For example, ventilation and perfusion are preferentially distributed to the lung bases in the upright posture, and this may account for the predominant involvement of the lower lung in smoker's bronchitis and in emphysema associated with $\alpha_{1}$ anti-trypsin deficiency. ${ }^{4}$ The extreme lung apex receives some ventilation but no perfusion and thus provides an oxygen-rich but ischaemic environment, which is said to favour the proliferation of certain organisms, notably the tubercle bacillus. ${ }^{5}$

Not only ventilation and perfusion but also inflationary stresses are unevenly distributed between the upper and lower parts of the lung. ${ }^{6}$ Distortion of the upright lung by its own weight causes higher negative intrapleural pressures ${ }^{7}$ and more fully distended alveoli 89 at the apex than at the base. These circumstances should favour the development, expansion, and rupture of abnormal air spaces in the upper lobes and may thus explain the predilection for this site of centrilobular $^{10}$ and non-bronchitic bullous ${ }^{11}$ emphysema, tuberculous cavitation, and the causative lesion in idiopathic pneumothorax. ${ }^{3}$

Distortion by gravity should be greater in lungs with a large vertical height, and so this mechanical hypothesis receives some support from the observation that young men with pneumothorax tend to be above average height ${ }^{312} 13$ and that, in one reported series, ${ }^{11}$ patients with apical bullous emphysema were on average 3 in $(8 \mathrm{~cm})$ taller than those with bronchitis and predominantly basal disease. The intractable cavitation which may complicate apical fibrosis in patients with ankylosing spondylitis ${ }^{14}$ could be explained on a similar mechanical basis. Ankylosis of the costovertebral joints impedes expansion of the lung, and since the deflated lung is also more flaccid it is more readily distorted by its own weight. ${ }^{6}$ The increased vertical action of the diaphragm in these cases would further add to the stresses on the lung apex.

To return to the problem of pneumothorax in young men: it may be that relative ischaemia of the lung apex makes this part more susceptible to infective lesions of various kinds; the subsequent expansion and rupture of a bulla accompanying such a lesion may then be determined by gravitational stresses. This apical localization of the disease process in idiopathic pneumothorax certainly justifies the view expressed by Lichter and Gwynne ${ }^{3}$ that wedge resection is a more rational treatment than the instillation of pleural irritants.

If gravity is indeed a cause of some apical forms of emphysema, cavitation, and pneumothorax, these conditions could now be listed with inguinal hernia and uterine prolapse as the penalties for man's assumption of the erect posture.

1 British Medical fournal, 1968, 1, 720

Killen, D. A., and Gobbell, W. G., Spontaneous Pneumothorax, Boston, Little, Brown, 1968.

${ }^{3}$ Lichter, I., and Gwynne, J. F., Thorax, 1971, 26, 409

4 British Medical fournal, 1971, 3, 655.

5 Riley, R. L., Bulletin of the fohns Hopkins Hospital, 1960, 106, 232.

6 Riley, R. L., Bulletin of the fohns

7 Krueger, J. J., Bain, T., and Patterson, J. L., fournal of Applied Physiology, $1961,16,465$.

${ }^{8}$ Milic-Emili, J., Henderson, J. A. M., Dolovich, M. B., Trop, D., and Kaneko, K., Fournal of Applied Physiology, 1966, 21, 749.

${ }^{9}$ Glazier, J. B., Hughes, J. M. B., Maloney, J. E., and West, J. B., fournal of Applied Physiology, 1967, 23, 694.

10 Thurlbeck, W. M., American Review of Respiratory Diseases, 1963, 87, 206.

11 Ogilvie, C., and Catterall, M., Thorax, 1959, 14, 216.

12 Withers, J. N., Fishback, M. E., Kiehl, P. V., and Hannon, J. L., 1964, American fournal of Surgery, 108, 772.

13 Forgacs, P., Thorax, 1967, 22, 481.

14 British Medical fournal, 1971, 3, 492. 